\title{
DIÁLOGOS INTERCULTURAIS E AS POTENCIALIDADES DA LEI 11.645-08: OUTROS ESPAÇOS DE APRENDIZAGENS, OUTRAS LEITURAS DE MUNDO
}

\author{
Maria de Fátima Barbosa da Silva ${ }^{(*)}$ \\ "Em toda fronteira há arames rígidos e arames caídos" \\ Néstor Garcia Canclini
}

O texto em epígrafe nos ajuda na compreensão de que mesmo em fronteiras sólidas, como as tradições que envolvem as produções de saber, é possível e necessário buscarmos caminhos de abertura para o “novo”. Entre muitos caminhos, alguns vêm se alentando, oficialmente, no Brasil, a partir de um corpo jurídico que visa propostas paritárias de direitos, no tocante as relações étnicas e culturais.

A lei 11.645-08 representa um marco importante para superação das fronteiras que foram sendo construídas, socialmente, ao longo da nossa História e resultaram em discriminações e preconceitos, na forma como determinados grupos e culturas foram representados nos livros didáticos, nos currículos de História, bem como em consequentes formas de segregação e marginalização na sociedade. Anteriormente a esta lei, fora assinada, em 2003, a lei 10.639, cujo foco concentrava-se na temática africana, enquanto a lei 11.645-08 acrescentou a questão indígena, ambas modificando a nossa atual Lei de Diretrizes e Bases da Educação (LDB/1996). A inclusão destas temáticas vem provocando mudanças em nossas concepções de saber, uma vez que ao olharmos para outras matrizes que não a eurocêntrica, podemos fazer emergir outras cosmovisões, cujos efeitos poderão gerar novos reordenamentos de saberes.

Neste sentido, este trabalho se insere como uma proposta de reflexão em favor de novas possibilidades para produção de conhecimentos, com foco no diálogo entre as culturas: uma perspectiva intercultural para o ensino de História. Como base no cenário urbano da cidade de Niterói (RJ), como contexto replicável, propõe-se algumas metodologias para implementação da lei 11.645-08. Niterói (RJ) é um campo no qual as relações entre grupos culturais distintos são verificáveis nas marcas desarticuladas do passado em um mesmo presente. Algo que não lhe é

\footnotetext{
${ }^{(*)}$ Professora na rede municipal de Educação em Niterói (RJ). Doutoranda no programa de Pós-Graduação em Educação (UFRJ), Integrante do Laboratório do Núcleo de Estudos do Currículo/LANEC/UFRJ, integrante do Laboratório de Estudos e Pesquisas em Ensino De História/LEPEH/UFRJ e integrante do Grupo de Estudos e Pesquisas em Ensino de História e Formação de Professores/GEHPROF/UFRJ. Mestre em Ensino pelo Programa de Pós Graduação em Educação Básica PPGEB/UERJ. E-mail: silvamfbs@gmail.com.
} 
exclusivo. Diversamente, é verificável em muitas outras conjunturas. A proposta para estas metodologias é deslocar concepções etnocêntricas para narrativas plurais. Por meio de histórias entrecruzadas, construir pontes entre os conteúdos tradicionais da disciplina da História e os saberes dos grupos culturais silenciados, e, simultaneamente, enunciar o seu protagonismo.

Estas metodologias foram experimentadas em turmas de oitavo e nono ano da Escola Municipal Altivo César, situada em Niterói (RJ), como campo empírico para aferição do alcance das propostas com foco na interculturalidade. Elas procuravam provocar, entre outros efeitos, a alteridade do estudante por meio do (re) conhecimento de outras realidades no tempo. Uma perspectiva de “encontro" neste front de muitas culturas. Encontros do "eu” com o "outro”, nos tensionamentos dos arames estendidos no tempo formadores de nossas identidades.

\section{NOS MARCOS HISTÓRICOS E JURÍDICOS DA LEI 11.645-08: UMA PONTE PARA IGUALDADE POR CAMINHOS INTERCULTURAIS}

Toda a legislação possui atrás de si uma história do ponto de vista social. As disposições legais não são apenas um exercício dos legisladores. Estes, juntos com caráter próprio da representatividade parlamentar, expressam a multiplicidade das forças sociais Conselho Nacional de Educação Câmara de Educação Básica

A trajetória das leis 11.645-08 e 10.639-03 é fruto da mobilização da sociedade, expressando esta multiplicidade das forças sociais, especialmente dos grupos, assim denominados minoritários, em termos de representatividade. ${ }^{1}$ Pode-se considerar que seu embrião, nasce no contexto de mobilização política pelo retorno da democracia em nosso país, após o regime de exceção, do período da ditadura civil-militar.

Com a mudança do regime, assiste-se a promulgação de uma nova Constituição que visava construir uma realidade mais democrática. Todavia como proporcionar experiências pautadas nesta nova realidade, sem garantir direitos básicos, como o direito da existência e da valorização das identidades e culturas, em um país, como o nosso, em que se verifica uma enorme pluralidade cultural, sem contudo, que visualizemos o respeito necessário às diferenças?

\footnotetext{
${ }^{1}$ Uma das melhores definições para o conceito de grupos minoritários é a de Miguel Arroyo. Relaciona-se à questão do equilíbrio de forças no jogo da representação política e não em termos numéricos: "nos remete a coletivos concretos, históricos, as classes sociais e os grupos subalternizados, os oprimidos pelas diferentes formas de dominação econômica, política, cultural. (...) Focaliza-os não como pacientes, passivos e submissos, mas em ações, resistências, lutas e organizações, se fazendo presentes como atores na cena social, política, cultural e na produção de saberes. Reagindo a seu silenciamento” (ARROYO, 2009, p. 1).
} 
Em termos de proposição de garantias de direitos no tocante as relações étnicas e culturais, a Constituição de 1988, inegavelmente, representou um grande avanço: situações que envolvem, por exemplo, discriminações e preconceitos, sobretudo por questões relativas à cor da pele do indivíduo ou aos seus aspectos culturais, atualmente são considerados crimes inafiançáveis.

Obviamente, quando assumimos uma consciência crítica em relação a estas questões, tais inciativas deixam de ser necessárias, por isso é fundamental que nossos estudantes aprendam a respeitar as diferenças não em face de uma sanção legal, mas por uma mudança de mentalidade que contemple a sua cidadania.

Muitos brasileiros desconhecem que a nossa constituição é (re) conhecida, para além de nossas fronteiras, como “Constituição Cidadã”. Considerada uma das mais democráticas do mundo, por incluir as demandas de diversos setores da sociedade civil, não sem um grande embate de forças. E é ainda neste embate, que precisamos consolidá-la, transpondo-a da teoria, em direção a uma prática mais efetiva na nossa sociedade.

A prática cotidiana das escolas pode ser um terreno fértil, no qual se produzirão os efeitos mais duradouros para materialização do nosso ordenamento jurídico, especialmente no que tange a temática da nossa pluralidade cultural. Além da nossa carta magna, outros instrumentos foram se constituindo até culminar no texto da lei 11.645-08. Alguns instrumentos conseguiram avançar mais que outros, considerando-se que na arena política, travam-se muitas disputas.

Podemos citar como conquistas nestas disputas políticas, os Parâmetros Curriculares Nacionais (PCNs), ao incluir o eixo transversal da pluralidade cultural, a criação de diversas secretarias federais e regionais, com o objetivo de combater o racismo e outras formas de discriminações culturais, a Lei de Diretrizes e Bases da Educação (LDB/1996), conhecida como lei Darcy Ribeiro, também em consonância com a nova realidade de Estado Democrático de Direito, a qual contribuiu de modo significativo para o enfrentamento desta problemática, e por fim, os acréscimos à LDB/1996 por meio das leis 10.639-03 e 11.645-08, àquela ao enunciar a temática da questão africana, e, esta ao incluir a temática indígena nas escolas brasileiras.

A inclusão destas temáticas vem provocando mudanças na concepção do saber escolar e também acadêmico, na medida em que ao se olhar para outras matrizes para além daquela que é a hegemônica, isto é, a europeia, outros saberes e novas visões de mundo passam a ser enunciadas e como resultado tem-se um reordenamento de caráter epistemológico.

Considerando-se o embate de forças que permeia as relações sociais de produção do conhecimento, a professora Ana Maria Ferreira da Costa Monteiro (UFRJ) advoga que o saber 
escolar possui uma dinâmica própria que dialoga com os saberes acadêmicos e outras instâncias da noosfera (termo utilizado para designar as instâncias para seleção de conteúdos curriculares, que ultrapassam a sala de aula). Para ela não há que se hierarquizar estes saberes, pois possuem públicos e finalidades distintas, mas ambos envolvem densas elaborações. (MONTEIRO, 2001, p.126). É com foco nestas elaborações, que o próximo tópico intenciona refletir, nas dicotômicas tensões entre saberes e poderes.

\section{POR UMA EPISTEMOLOGIA PLURAL: ENTRE SABERES E PODERES.}

O currículo é também uma relação social, no sentido de que a produção de conhecimento que é visto como coisa foi produzido através de relações sociais _ e de relações sociais de poder.

Tomás Tadeu da Silva

Como nos alerta Tomás Tadeu da Silva,os currículos são artefatos que devem ser vistos, para além das relações de consumo. Devemos compreendê-lo em seu caráter produtivo e, com isto, as relações de poder engendradas. A seleção dos conteúdos, é permeada de tensões políticas. São elas que validam a distinção dos grupos que podem ser representados e de que modo (SILVA, 2009: 193 e 194).

Há, assim, um controle sobre a produção dos discursos curriculares: um amálgama entre saberes e poderes, em tramas rígidas ou mais flexíveis. Segundo o filósofo Michael de Foucault, existe uma relação entre os discursos e àquilo que somos. São os discursos que nós constituem como sujeitos. Neles, não há neutralidade, posto que são construídos a partir de uma única palavra: o poder.Ele irá impactar a nossa subjetividade, já que as suas relações estão presentes nos diversos aspectos da vida em coletividade e da qual somos participantes. Há poder, porque somos múltiplos.

O poder se estabelece como forma da organização da vida na coletividade, objetivando-se a harmonia entre os pares, isto é, entre os seres humanos. Operam, entretanto forças desestabilizadoras, entre as quais, as discordâncias, as desigualdades e as diferenças, entre outros fenômenos.É preciso ter em mente, que nem toda relação de poder emana de um centro. Diversamente, as relações de poder encontram-se diluídas nas tramas dos tecidos sociais. Segundo o filósofo Michael de Foucault, elas ainda podem ser benéficas e pendulares, em consonância com o modo com o qual nelas operamos (DEACON, 1994, p. 10 apud DEACON; PARKER, 2008, p. 102).

Segundo o professor Mario Sérgio Cortella (PUC-SP), as relações de poder, nos sãos úteis como forma de progresso da evolução humana. É imprescindível, pois, desenvolvermos a nossa 
autonomia, nosso senso crítico e nosso protagonismo, de modo que possamos nos relacionar com as dimensões de poder de modo não passivo, mas ativamente.

O poder se estabelece como meio organizacional da vida, uma vez que, vivemos em multiplicidade, uns com os outros. Quando estas relações são, predominantemente, harmônicas, podemos verificar a presença do conflito. Algo que é natural à convivência humana, pois sempre haverá divergências no que concerne às regras, às hierarquias e a outros postulados do poder. Será positivo, segundo o professor Mário Sergio Cortella (PUC -SP) pois possibilita elevar a condição da vida humana em sociedade. Contudo, nas relações de poder assimétricas, a sociedade está sob risco, já que o poder se torna um desafiador, ou uma ameaça às vontades, nem sempre concordantes entre si. Verifica-se então, a presença do confronto. Ele tende a anular vontades e submeter os indivíduos. Por isso, segundo Cortella, o confronto é negativo.

As janelas do passado nos mostram que as relações entre as múltiplas culturas neste solo Brasil, tem sido operacionalizada muito mais pela perspectiva do confronto. Produziram segregações, devido às relações desarmônicas, geradoras também de apagamentos e várias formas de explorações, tanto para indígenas, que foram sendo expropriados de seus espaços quanto para africanos transmigrados forçosamente, nem sempre provenientes das mesmas regiões o que, portanto já, produzia segmentações.

\section{O DIÁLOGO COMO OPÇÃO}

Diante deste quadro, em que se operam relações desarmônicas ao longo do nosso percurso histórico, no contato com povos de inúmeras matrizes culturais, precisamos trilhar caminhos que nos levem a paridade de direitos e ao respeito às diferenças. Neste sentido, uma abordagem com foco nos Estudos Culturais é contributiva para (re) pensarmos o modo como dialogamos com os diversos saberes.

Para o campo dos Estudos Culturais, Educação e Cultura são inesperáveis: há uma intencionalidade pedagógica na cultura e toda Educação é cultural:

Tal como a educação, as outras instâncias culturais também são pedagógicas, também têm uma "pedagogia”, também ensinam alguma coisa. Tanto a educação quanto a cultura em geral estão envolvidas em processos de transformação da identidade e da subjetividade (SILVA, 2015, p. 139).

Os Estudos Culturais compreendem os sistemas de significação não apenas restritos aos saberes formais e eruditos, encapados pelo saber acadêmico; dos espaços formais de Educação, 
como as escolas e as universidades. Defendem que é possível a construção de projetos pedagógicos em outras instâncias, que vão desde os museus, documentários e, inclusive, indústrias culturais de massa como a Disney e os “fastfoods”.

Estes espaços são denominados de espaços não formais de educação, conceito proveniente do campo dos Estudos Culturais. Eles estão ao alcance do nosso cotidiano. Educando-nos, mesmo quando consideramos que não há tal intencionalidade. Intencionando-se mobilizar outras concepções de saberes, buscou-se aproveitar as potencialidades destes dois espaços de formação (formais e não formais) e nesse sentido, foram propostas práticas pedagógicas para efetivação da lei 11.645-08, com metodologias que intencionavam produzir novos sistemas de significações culturais no contexto dos estudantes. Elas possuíam como foco a observação de como se deram as trocas culturais entre nossas matrizes em diversos contextos relacionais. Tais contextos relacionais podem ser compreendidos a partir de uma:

[...] concepção de educação (como contexto integrador entre diferentes sujeitos e entre seus respectivos contextos culturais) e de educador (como o articulador de mediações) (que) ganha agora um novo enfoque, a partir dos estudos que vimos realizando sobre $o$ hibridismo da identidade dos sujeitos e de seus contextos culturais (FLEURI, 2002, p. 410).

Possibilitar ao estudante o encontro com outras realidades no tempo através da metodologia desenvolvida neste trabalho traduz o esforço de elevar a alteridade do aluno e, simultaneamente, aprofundar o encontro dele consigo e dentro da comunidade escolar. A opção pelo hibridismo da identidade dos sujeitos e de seus contextos culturais é uma das apostas da perspectiva intercultural para dar conta das tensões resultantes dos choques conflitivos do nosso percurso colonizatório. Uma resposta emancipatória a este processo que se perpetua no tempo.

É emancipatória, pois esta perspectiva defende a necessidade da intensificação nas trocas culturais, consciente de que é necessário democratizar os espaços para que as culturas possam se relacionar entre si de modo mais igualitário. Defende que é primordial a ampliação das margens para efetivação destas trocas frente aos sistemas culturais dominantes.

Assim, convém analisar algumas propostas de autores vinculados aos Estudos Culturais, especialmente por perseguir estas linhas de fronteiras culturais. Reinaldo Fleuri converge neste princípio, aproximando a discussão ainda mais do campo do ensino. Este autor introduz uma importante questão na análise dos intercâmbios entre as identidades culturais, que consiste no problema em “como promover o respeito entre as culturas integrando-as sem anulá-las” (FLEURI, 2003, p. 17). 
A aposta deste autor é àquela com a qual se identifica este trabalho: a Educação Intercultural, para a qual foram feitas algumas alusões, anteriormente. Podemos defini-la como “uma proposta de 'educação para a alteridade’, aos direitos do outro, à igualdade de dignidade e de oportunidades, uma proposta democrática ampla [...] Trata-se, na realidade, de um novo ponto de vista baseado no respeito à diferença, que se concretiza no reconhecimento da paridade de direitos (FLEURI, 2003, p. 17). O termo tem em sua trajetória, contribuições de diversos pesquisadores de várias nacionalidades, em que:

[...] descortinam novas perspectivas de compreensão das diferenças e das identidades culturais no campo das práticas educativas. Para além de uma compreensão rígida, hierarquizante, disciplinar, normalizadora da diversidade cultural, emerge o campo híbrido, fluido, polissêmico, ao mesmo tempo trágico e promissor da diferença, que se constitui nos entrelugares e nos entreolhares das enunciações de diferentes sujeitos e identidades socioculturais (Idem, p. 30).

A terminologia com vistas a proporcionar a igualdade de direitos vem se estabelecendo, praticamente desde a década de 1990:

A dificuldade de se controlar o entrelaçamento da terminologia e de interpretar corretamente o conjunto das diferentes propostas, impede-nos de produzir esquemas simplificatórios eficazes [...] (Idem, p. 17).

Tal dificuldade ressalta da seara complexa que envolve diversas nomenclaturas:

Para além da polissemia terminológica e da evidente diversidade de perspectivas que se expressam nas teorias e propostas relativas ao multiculturalismo, interculturalismo, transculturalismo, constitui-se um campo de debate que se torna paradigmático justamente por sua complexidade: a sua riqueza consiste justamente na multiplicidade de perspectivas que interagem e que não podem ser reduzidas por um único código e um único esquema a ser proposto como modelo transferível universalmente (Idem).

Entre as diversas correntes que buscam compreender os complexos processos de convívios culturais (nem sempre harmônicos) a opção pela Educação Intercultural se justifica, na medida em que se propões a estabelecer diálogos, entre as diversas culturas, buscando pontos de contato, na perspectiva de que: as culturas influenciam umas às outras, criam propostas de resistências às consideradas culturas dominantes (contracultura) e em decorrência destas interações, constroem novos artefatos culturais, artefatos híbridos.

Desta forma, ao visar o diálogo, a partir do encontro entre culturas, a Educação Intercultural se constitui também em possibilidade prática de intervenção. Para isto, há a necessidade de se investigar metodologias que permitam aos estudantes o reconhecimento destes pontos de contato. 
Ao assimilar a hibridação, como elemento vivo em cada contexto, seria possível a construção do respeito às diferenças pelo olhar da alteridade.

Nas recentes pesquisas no campo da Educação Intercultural, o próprio conceito de Educação vem passando por um processo de ressignificação: “entendida como a promoção de contextos e processos relacionais estratégicos que permitam a articulação entre diferentes contextos culturais”. (FLEURI, 2002, p. 5)

Neste sentido, a Educação deixaria de ser promotora de programas e conteúdos mas de contextos que permitam a interação entre diversos sujeitos, nos quais se valorizem as diferenças culturais. O professor, dentro desta concepção de Educação, assume o papel de mediador:

[...] se o processo educativo consiste na criação e desenvolvimento de contextos educativos e não simplesmente na transmissão e assimilação disciplinar de informações especializadas, ao educador compete a tarefa de propor estímulos (energia colateral) que ativem as diferenças entre os sujeitos e entre seus contextos (histórias, culturas, organizações sociais...) de modo a desencadear a elaboração e circulação de informações (versões codificadas das diferenças e transformações) que se articulem em diferentes níveis de organização (seja em âmbito subjetivo, intersubjetivo, coletivo, seja em níveis lógicos diferentes) (FLEURI, 2003, p. 32).

Ao propor os estímulos capazes de despertar o olhar dos estudantes para o respeito às diferenças, o educador se insere em um processo de contínua reelaboração, favorecendo uma aprendizagem em consonância com as próprias dinamicidades históricas e sociais: Educador, neste sentido, é propriamente um sujeito que se insere num processo educativo, e interage com outros sujeitos dedicando particular atenção às relações e aos contextos que vão se criando, de modo a contribuir para a explicitação e elaboração dos sentidos (percepção, significado e direção) que os sujeitos em relação constroem e reconstroem (FLEURI, 2000, p. 12).

Os currículos, em uma proposta pedagógica intercultural, não se limitam apenas ao acréscimo de conteúdos. Ao contrário, precisam reconfigurar-se no sentido de dialogar entre os sujeitos e seus saberes em variados contextos:

Nestes contextos, o currículo e a programação didática, mais do que um caráter lógico, terão uma função ecológica, ou seja, sua tarefa não será meramente a de configurar um referencial teórico para o repasse hierárquico e progressivo de informações, mas terá a tarefa de prever e preparar recursos capazes de ativar a elaboração e circulação de informações entre sujeitos, de modo que se auto-organizem em relação de reciprocidade entre si e com o próprio ambiente (FLEURI, 2003, p. 32). 
É nesta relação, justamente, em que se percebe a produção de saberes em reciprocidade e vai ao encontro das recomendações nas diretrizes curriculares para as relações culturais:

É importante destacar que não se trata de mudar um foco etnocêntrico marcadamente de raiz europeia por um africano (ou indígena), mas de ampliar o foco dos currículos escolares para a diversidade cultural, racial, social e econômica brasileira [...] É preciso ter clareza que o Art. 26A acrescido à Lei 9.394/1996 provoca bem mais do que inclusão de novos conteúdos, exige que se repensem relações étnico-raciais, sociais, pedagógicas, procedimentos de ensino, condições oferecidas para aprendizagem objetivos tácitos e explícitos da educação oferecida pelas escolas (BRASIL, 2004, p. 26).

Elencar as culturas, colocando-as lado a lado, ou o que é pior, hierarquizando-as, reforça o caráter desigual dos processos produtores de assimetrias na forma como as culturas são representadas e no reconhecimento de direitos. Não condiz, com o modo pelo o qual elas interagem na prática. Um olhar sobre os contextos de interação, tal como ocorrem nos cenários urbanos, nos ajuda a compreender os embates travados e suas marcas dispersas no tempo.

Néstor Garcia Canclini, teórico da perspectiva intercultural, advoga que as culturas ao interagirem umas com as outras produzem artefatos híbridos. Ele julga o termo híbrido mais adequado que sincretismo, pois este refere-se apenas a práticas religiosas e do que mestiçagem, pois refere-se apenas a elementos genéticos. O hibridismo possui, segundo este autor, uma amplitude maior. Trata-se de um empréstimo da biologia, no qual elementos da cultura A se mesclam a elementos da cultura B e produzem artefatos novos, que não correspondem apenas a A e B, são artefatos híbridos que em conjunto formam uma nova cultura, C.

Canclini apresenta vasta teoria sobre o conceito de hibridação, um dos fenômenos resultantes da interculturalidade, a qual pode ser compreendida entre outros fatores, através do que este autor denomina de “desterritorialização”. Podemos compreender melhor este conceito, se observarmos o nosso processo colonizatório, que incluiu a imigração dos portugueses e dos africanos (forçadamente, desenraizando-os), produzindo as expropriações indígenas, bem como outros movimentos de imigração ao longo do nosso percurso histórico (CANCLINI, 2013, p. 309 a 336).

Ele defende que para compreender e atuar na realidade dos países que vivenciaram a colonização e seus efeitos, é necessário romper com as antigas lógicas explicativas pautadas em concepções estruturalistas e hierárquicas de mundo, nos quais se verificam os binômios centro- 
periferia, imperialistas-colonizados, saberes eruditos e saberes populares. Isto porque, no contexto atual, os capitais se tornam supranacionais, especialmente pelo progresso das telecomunicações:

Esse modelo é insuficiente para entender as atuais relações de poder. Não explica o funcionamento planetário de um sistema industrial, tecnológico, financeiro e cultural, cuja sede não está em uma só nação mas em uma densa rede de estruturas econômicas e ideológicas [...] A disseminação de produtos simbólicos pela eletrônica e pela telemática, o uso de satélites e computadores na difusão cultural também impedem de continuar vendo os confrontos dos países periféricos como combates frontais com nações geograficamente definidas (CANCLINI, 2013, p. 310).

Esta percepção que ultrapassa a antiga fórmula dos combates frontais, auxilia na composição de práticas que se pautem na perspectiva de valorização das identidades. O combate às relações desiguais, é deslocado para o lócus privilegiado dos sujeitos que ali estejam inseridos, tal como ocorrem, atualmente, nas cidades:

Destaco as fronteiras entre países e as grandes cidades como contextos que condicionam os formatos, os estilos e as contradições específicos da hibridação [...] Poucas culturas podem ser descritas como unidades estáveis, com limites precisos baseados na ocupação de um território delimitado [...] são estudadas como centros em que a hibridação fomenta maiores conflitos e maior criatividade cultural (Idem, 2013, p. 29 a 30).

Para sua pesquisa, Canclini elegeu a cidade do México, sustentado que:

Dentro da cidade, são seus contextos familiares, de bairro e de trabalho, os que controlam a homogeneidade do consumo, os desvios nos gostos e nos gastos. Numa escala mais ampla, "o que” se entende como cultura nacional continua servindo de contexto para seleção do exógeno [...] Contudo, estas comunidades de pertencimento e controle estão se reestruturando. A que conjunto a participação numa sociedade construída predominantemente pelos processos globalizados de consumo nos faz pertencer? (Idem, p. 61).

A problemática do pertencimento é fundamental para as identidades, principalmente se observarmos as políticas culturais urbanas na América Latina, como as que por ele foram elencadas em seus trabalhos. São perceptíveis como as referências nacionais e locais estão sendo diluídas, por intermédio dos filmes, publicidades, novelas, e assim, os lugares mais distantes acabam assimilando características das grandes metrópoles. Alterando os seus cenários, por exemplo:

A cidade já não e mais vista como mero cenário para habitação e o trabalho, ou seja, como simples organização espacial, lugar de assentamento da indústria e dos serviços 
[...] A caracterização sócio-demográfica do espaço urbano não consegue dar conta de seus novos significados se não incluir também a recomposição que a ação midiática lhes imprime [...] Partimos da questão de como são constituídos hoje os imaginários em uma megacidade. Por outro lado, também nos perguntamos sobre como se configuravam no passado (Idem, p. 41 e 42).

Com a expectativa de enunciar estes novos significados, como um dos caminhos possíveis para o fim dos distanciamentos, pautados nos preconceitos e discriminações, e assim, atuar na perspectiva da paridade de direitos, o próximo item irá apresentar alguns resultados por meio da mobilização da teoria intercultural na prática. Intenciona-se a construção de pontes no lugar das nossas fronteiras simbólicas.

\section{UMA CIDADE, UM SISTEMA DE SIGNIFICAÇÕES (INTER) CULTURAIS: POTENCIALIDADES DA LEI 11.645-08 NO CONTEXTO DA PRÁTICA}

Com todo povo de Ismael, que desta terra é filho seu Tornando o mundo a sua escola e o samba o seu lugar (Sinopse do samba enredo da Unidos da Viradouro, 2014).

Fortuitamente, o samba da Viradouro, que ganhou a apoteose ao lado de escolas de outros municípios bradou pela identidade histórica de Niterói, no ano que se iniciou a pesquisa, em nível de mestrado, para elaboração de metodologias, com vistas a efetivação da lei 11.645-08. Pela proximidade entre o barracão e a escola municipal Altivo César, campo empírico para experimentação das metodologias desenvolvidas, foi possível uma atividade de campo, com o objetivo de levarem os estudantes a presenciarem esta arte, por excelência híbrida. No intuito de fomentar a vivência a respeito dos sistemas de significações culturais, outras atividades de campo foram desenvolvidas como parte da experimentação da teoria intercultural aplicada ao Ensino de História.

O samba abordava o encontro das três culturas (indígena, portuguesa e africana), ao mesmo tempo em que valorizava a identidade local, em versos que entonavam o “orgulho de ser Niterói”. Esta identidade local é coadjuvante de muitas outras, que igualmente precisam ser enunciadas, em uma perspectiva fragmentária e híbrida, tal como foi postulada pelo teórico jamaicano Stuart Hall:

A identidade torna-se uma 'celebração móvel’: formada e transformada continuamente em relação às formas pelas quais somos representados ou interpolados nos sistemas culturais que nos rodeiam... Definida historicamente, e não biologicamente (HALL, 1998, p. 13). 
No encontro destas três matrizes, há que se refletir a respeito dos vínculos criados e como eles proporcionam para a cidade o que ela é hoje, e mais, o que poderá vir a ser. Para o estudante, cabe destacar a necessidade de sua atuação neste lócus para nutrir sua condição de cidadão participativo em coletividade, como sugere o samba, o "artista deste palco”.

Este samba possibilitou a criação de situações-problemas, por meio de uma perspectiva intercultural, especialmente, por falar da relação histórica entre lugares: Niterói e o Rio de Janeiro. Esta última metonímia por muito tempo da própria nação Brasil, espelhando outras histórias mais amplas. Em sua sinopse já se enuncia um dos princípios que move esta pesquisa com foco no Ensino de História: nossa escola é o mundo.

A abordagem curricular com foco intercultural foi operacionalizada em turmas de oitavo ano e nono ano, e um dos temas tratados foi “O reinado de D. Pedro II: modernização e imigração”. A partir de uma seleção documental, bem como de reportagens atuais, que valorizava o protagonismo de outros agentes para além deste grande vulto, a aula apresentou como situação-problema, a questão do trabalho, as condições de vida dos imigrantes, o desemprego e as condições sociais dos ex-escravos pós abolição.

“Nos trilhos da história, a evolução”, como sugere o samba enredo da Unidos da Viradouro, os alunos foram convidados a refletir sobre os espaços da cidade que abrigavam estas múltiplas identidades em um único território, com espelhamentos para os espaços simbólicos em outras amplitudes. As segregações, silenciamentos e exclusões como marca não apenas da cidade, mas de contextos mais ampliados.

O aporte documental ${ }^{2}$ favoreceu a exposição de ideias e problemas compartilhados por aqueles estudantes, especialmente, no tocante a questão do desemprego, da renda e da Educação, como necessidade para progressão coletiva e individual. Com base na documentação, eles inferiram que a condição do imigrante era também muito precária e fizeram associações com os surtos de doenças na época. Os estudantes conseguiram relacionar estes documentos às condições do mundo do capitalismo e suas formas de exploração, que remontavam ao período da acumulação primitiva de capital e suas relações com os processos colonizatórios.

Como atividade de campo, eles visitaram a hospedaria da Ilha das Flores em São Gonçalo (RJ), município fronteiriço a Niterói. Esta hospedaria, atualmente é um museu a céu aberto (anexo 1). Seu uso no passado correspondia a primeira moradia e provisória dos imigrantes em nosso país.

\footnotetext{
${ }^{2}$ Este aporte documental encontra-se no livro Diálogos Interculturais no Ensino de História: Oficinas Pedagógicas para aplicação da lei 11.645-08 de minha autoria.
} 
Lá perceberam o cotidiano dos povos oriundos de diversos países do mundo, os choques culturais, encampados pelos sonhos de prosperidade. E perceberam as contradições que se impunham tanto para estes novos residentes do país quanto para os antigos. As documentações e a atividade de meio foram retomadas ao longo do ano letivo, para problematização de outros temas curriculares.

Os estudantes empreenderam diversas produções, a partir desta experimentação prática, com destaque para a produção escrita em uma plataforma online, denominada "wikianiterointercultura”3 . Esta plataforma possuía acesso direto com as redes sociais dos estudantes, mobilizando seus grupos de convívios ao compartilhamento destas aprendizagens.

Os estudantes se apropriaram de caminhos para resistência cultural, ao perceber os rastros silenciados na tessitura social: artefatos de museu que davam conta deste mundo de trabalho tão desigual, que os levaram a refletir sobre sua própria condição no mundo. Refletir sobre si mesmo, naquele momento, correspondia a fugir de tramas eurocêntricas, e a possibilidade de ressignificar a disciplina História por meio desta visita a outros protagonistas do nosso passado.

\section{CONCLUSÕES:}

No desenvolvimento desta pesquisa, buscou-se um diálogo entre a escola, a sala de aula e o contexto dos estudantes. O objetivo era levá-los a enxergar para além dos muros da escola, toda a riqueza cultural, que é estar no lugar de encontros, de hibridações e com isto, estabelecer através do reconhecimento da alteridade, práticas cidadãs de convivências.

A nossa cidade, que por vezes é desvalorizada, na perspectiva da interculturalidade, assume uma função de despertar o interesse no estudante de ouvir suas histórias na expectativa de equalizar relações de poder intrínsecas a escala do micro, no cotidiano destes jovens. A cidade passa, então, a ter outro significado, uma nova importância: percebida, sentida e interpretada de modo diferente. Torna-se um espaço de múltiplas convivências, mas também de atuação, de protagonismo. Há muitas descobertas nesta escola-mundo. E como o mundo não cabe na escola, há que se ultrapassar estas fronteiras.

\footnotetext{
${ }^{3} \mathrm{O}$ link para alguns relatos encontra-se nas referências.
} 


\section{REFERÊNCIAS}

ARROYO, Miguel G. Ações Coletivas e Conhecimento: Outras Pedagogias? Disponível em: <http://www.universidadepopular.org/site/media/leituras_upms/Acoes_Coletivas_e_Conhecimento__30-11-09.PDF>. Acesso: 10 ago. 2015.

BRASIL. Diretrizes Curriculares Nacionais para a Educação das Relações Étnico-Raciais. Brasília: MEC/SEF, 2004. Disponível em: <http://www.acaoeducativa.org.br/fdh/wp-content/uploads/2012/10/DCN-s-Educacao-dasRelacoes-Etnico-Raciais.pdf>. Acesso em: 27/10/2017.

CANCLINI, Nèstor Garcia. Cultura Híbridas: Estratégias para e Sair da Modernidade. 4. ed. São Paulo: Editora da Universidade de São Paulo, 2013.

DEACON, R. \& PARKER, B. Educação como sujeição e como recusa. In: SILVA, T. T. (Org.). O sujeito da educação: estudos foucaultianos. 6. ed. Petrópolis: Vozes, 2008. p. 97-110.

FLEURI, Reinaldo Matias. Educação Intercultural: desafios e perspectivas da identidade e pluralidade. PQ/CNPQ. Florianópolis, 2000.

Educação intercultural: a construção da identidade e da diferença nos movimentos sociais. PERSPECTIVA, Florianópolis, v. 20, n. 2, p. 405-423, jul./dez. 2002.

HALL, Stuart. A identidade cultural na pós-modernidade. Rio de Janeiro: DP\&A Editora, 1998.

MONTEIRO, Ana Maria Ferreira da Costa. Professores: entre saberes e práticas. Educação \& Sociedade, ano XXII, n. 74, abr. 2001. Disponível em: <http://www.scielo.br/pdf/es/v22n74/a08v2274.pdf>. Acesso em: 10 ago. 2015.

PRODUÇÃO DOS ESTUDANTES: HOSPEDARIA ILHA DAS FLORES. Disponível em: <http://pt-br.niterointer cultural.wikia.com/wiki/Hospedaria_ilha_das_flores>.

SILVA, Maria de Fátima Barbosa da. Diálogos Interculturais no Ensino de História: Oficinas Pedagógicas com aplicação da Lei 11.645-08. Rio de Janeiro: PoD editora, 2017.

SILVA, Tomaz Tadeu da "Currículo e identidade social: territórios contestados” In: SILVA, T. T. da. (Org.). Alienígenas na sala de aula. Uma introdução aos Estudos Culturais em Educação. 8. Ed. Petrópolis: Vozes, 2009.

2015.

Documentos de identidade: uma introdução às teorias do currículo. 3. ed. Belo Horizonte: Autentica Editora, 
Anexo 1. Atividade de campo na Hospedaria Ilha das Flores: Museu a céu aberto.

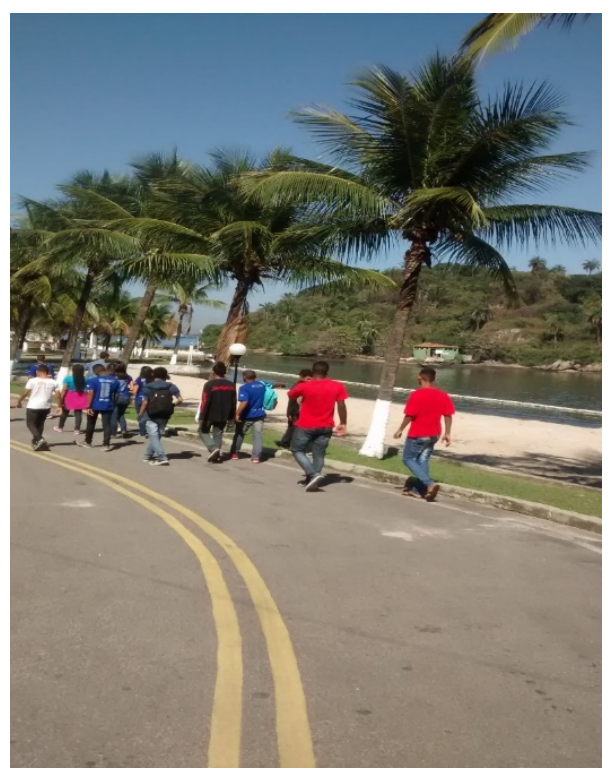




\section{RESUMO}

Este artigo objetiva externar alguns horizontes da lei 11.645-08, compreendendo-apor meio de princípios interculturais. Intenciona refletir sobre as bases conceituais da interculturalidade, as quais sugerem novos paradigmas para o ensino. Isto proporcionou a elaboração de metodologias para efetivação desta lei, experimentadas em turmas de oitavo e nono ano do Ensino Fundamental da Escola Municipal Altivo César, em Niterói (RJ), com caráter replicável.Defende-se que a perspectiva da pedagogia intercultural, é a de intervir na AÇÃO, em nossas práticas cotidianas em favor de diálogos entre as culturas, deslocando concepções etnocêntricas para narrativas plurais. Uma proposta democrática, em sentido amplo.

Palavras-chave: Ensino de História. Interculturalidade e Currículo.

\section{INTERCULTURAL DIALOGUES AND THE POTENTIALITIES OF LAW 11.645-08: OTHER LEARNING SPACES, OTHER WORLD READINGS}

\section{ABSTRACT}

This article aims to outline some horizons of law 11.645-08, understanding it through intercultural principles. Intends to reflect on the conceptual bases of interculturality, which suggest new paradigms for teaching. This allowed the elaboration of methodologies for the implementation of this law, which were tested in eighth and ninth grade classes at the Altivo César Municipal School, in Niterói (RJ), with a replicable character. It is argued that the perspective of intercultural pedagogy is to intervene in ACTION in our daily practices in favor of dialogues between cultures, shifting ethnocentric conceptions to plural narratives. A democratic proposal, in a broad sense.

Keywords: Teaching History. Interculturality and Curriculum.

\section{DIÁLOGOS INTERCULTURALES Y LAS POTENCIALIDADES DE LALEY 11.645-08: OTROSESPACIOS DE APRENDIZAJES, OTRASLECTURAS DE MUNDO}

\section{RESUMEN}

Este artículo objetiva externar algunos horizontes de laley 11.645-08, comprendiéndo la por medio de principios interculturales. Intenciona reflexionar sobre las bases conceptuales de la interculturalidad, las cuales sugieren nuevos paradigmas para la enseñanza. Esto proporciono la elaboración de metodologías para la efectividad de esta ley, experimentadas em clases de octavo y noveno año de la Enseñanza Fundamental de la Escuela Municipal Altivo César, en Niterói (RJ), con carácter replicable. Se defiende que la perspectiva de la pedagogía intercultural, es la de intervenir EN LA ACCIÓN, en nuestras prácticas cotidianas en favor de diálogos entre las culturas, desplazando concepciones etnocéntricas para narrativas plurales. Una propuesta democrática, en sentido amplio.

Palabras clave: Enseñanza de Historia. Interculturalidad y Curriculo. 